\title{
Aparelho deThomas Modificado associado ao pino intramedular na osteossíntese de tibiotarso em cacatua (Cacatua galerita)
}

\author{
A Modified Thomas Device with an intramedular pin in the tibiotarsus osteosynthesis in cacatua \\ (Cacatua galerita)
}

\section{Afonso Henrique Miranda, Luiz Antônio Franco da Silva, Leandro Guimarães Franco, Liliana Borges Menezes, Ediane Batista da Silva, Maria Ivete de Moura \& Gustavo Henrique Coutinho Ribeiro}

\begin{abstract}
RESUMO
Diante da quantidade de variáveis descritas com relação à técnica ideal de fixação de fraturas em aves, o presente trabalho objetivou descrever o tratamento cirúrgico de um caso de redução de fratura de tibiotarso em cacatua empregando a técnica de pinagem intramedular associada ao aparelho de Thomas modificado. Após a realização da cirurgia, a ausência de sinais clínicos sugestivos de comprometimento circulatório no local da fratura, tais como edema, cianose e necrose, associados à facilidade de locomoção, indicaram que o tipo de imobilização obtido com a muleta de Thomas foi adequado. O método de pinagem intramedular, associada ao aparelho de Thomas modificado, permitiu satisfatória estabilidade ao foco da fratura e adequada formação do calo ósseo, evidenciado pelos exames clínicos e radiográficos, sendo considerado eficiente na redução de fratura de tibiotarso em cacatua.
\end{abstract}

Descritores: ave, fratura, redução, muleta.

\section{ABSTRACT}

In spite of the existence of different methods of reduction of fractures already mentioned in birds, the choice of the ideal technique, factors such as the size and age of the birds, the time past since the break, the healing and the presence of intercurrent problems must be considered. In this context, the present study aimed to describe a case of surgical treatment of a broken tibiotarsus in a cacatua by using reduction with intramedular pin with a modified Thomas device as a method of external setting. The absence of suggestive clinical sign of circulatory involvement in the site of the break, such as edema, cyanosis and necrosis associated with the ease of movement indicated that the type of immobilization used with the Thomas crutch was appropriate. The intramedular pin method with the modified Thomas device allowed satisfactory stability to the focal point of the fracture. Adjusted formation of the bone callus shown by the clinical signs and x-rays examinations was considered efficient in the reduction of the fracture of the tibiotarsus in the cacatua.

Key words: bird, fracture, reduction, crutch. 


\section{INTRODUÇÃO}

Os princípios de osteossíntese em pássaros são os mesmos que os dos mamíferos: fixação rígida, alinhamento anatômico, aposição de fragmentos, assepsia e rápido retorno à função [14]. Em aves, as fraturas localizadas nos ossos dos membros torácicos e pélvicos podem ser reduzidas por meio de fixação interna ou externa. Dentre as técnicas de fixação interna, as placas metálicas e os pinos intramedulares são os mais freqüentemente utilizados. Na fixação externa, são empregados, além dos aparelhos já desenvolvidos, as placas de policloreto de vinila (PVC), as substâncias adesivas e o arame, utilizado na confecção da muleta de Thomas $[8,12,14]$. O uso do aparelho de Thomas, como método de fixação externa das fraturas, foi preconizado, inicialmente, por Schrieder, em 1933. Tal aparelho foi submetido a várias adaptações, destinadas ao tratamento de fraturas localizadas nos membros torácicos e pélvicos [13]. Em aves, o aparelho de Thomas foi utilizado com sucesso como método auxiliar de estabilização externa em artrodese de joelho [7].

$\mathrm{Na}$ escolha da técnica ideal, o tamanho e idade da ave, o tempo de evolução da fratura e a presença de problemas intercorrentes devem ser considerados [2]. Diante de tais fatores, existe a necessidade do desenvolvimento e adaptação de novas técnicas para esses animais, especialmente pelo número crescente de aves manejadas em cativeiro e sujeitas a tais alterações. Nesse contexto, o presente trabalho objetivou descrever o tratamento cirúrgico de um caso de fratura de tibiotarso em cacatua, utilizando-se redução com pinagem intramedular associada ao aparelho de Thomas modificado como método de fixação externa.

\section{RELATO DO CASO}

Foi atendida, no Hospital Veterinário da Escola de Veterinária da Universidade Federal de Goiás, uma cacatua, com três meses de idade, pesando 300 g, com histórico de traumatismo no membro pélvico esquerdo à aproximadamente 40 dias, de acordo com as informações do proprietário. Ao exame físico, observouse claudicação, aumento de volume no terço médio do tibiotarso esquerdo, e sensibilidade aumentada à palpação. Seqüencialmente, realizaram-se os exames radiográficos convencionais do membro acometido, observando-se presença de fratura no terço proximal do tibiotarso e presença de calo ósseo secundário, consolidado em noventa graus. Depois de confirmado o diagnóstico, optou-se pelo procedimento cirúrgico de redução e imobilização da fratura como método de tratamento.

A indução anestésica foi realizada com associação de tiletamina e zolazepam ${ }^{1}$, nas doses de 3,0 $\mathrm{mg} / \mathrm{kg}$ e $3,0 \mathrm{mg} / \mathrm{kg}$, respectivamente, por via intramuscular (IM) na região da musculatura peitoral. A mesma associação foi utilizada para a realização da manutenção anestésica. Como terapia analgésica, optou-se pela administração de cloridrato de tramadol ${ }^{2}$, na dose de $2,0 \mathrm{mg} / \mathrm{kg}$, IM, trinta minutos antes da indução anestésica. Após a indução, a ave foi posicionada em decúbito lateral direito e, as penas do membro acometido, removidas manualmente. No transoperatório, seguida da exposição do osso fraturado, promoveuse a ressecção do calo ósseo neoformado, seguida do debridamento das extremidades ósseas fraturadas e fixação interna com fio de Kirschner de meio milímetro de diâmetro. Na imobilização externa, utilizouse o aparelho de Thomas Modificado, confeccionado a partir de arame galvanizado de um milímetro de diâmetro (Figura 1A). A modificação constou na alteração do aro ovalado tradicional para a forma de sela que fixa no membro não fraturado, promovendo uma melhor adequação à estrutura anatômica do animal, conforme modelo anteriormente desenvolvido para cães [10] (Figura 1B e 1C). O tratamento pós-operatório constituiu-se de antibioticoterapia sistêmica durante oito dias, com $50 \mathrm{mg} / \mathrm{kg}$ de oxitetraciclina ${ }^{3}$ em intervalos de 48 horas, via IM. Como terapia anti-inflamatória, administrou-se $2 \mathrm{mg} / \mathrm{kg}$ de flunixin meglumine $^{4}$, a cada 24 horas, via IM, durante quatro dias consecutivos. Diariamente, realizou-se higienização da limpeza com solução fisiológica, até a completa cicatrização da ferida cirúrgica. A remoção do pino intramedular foi realizada diante do resultado do exame radiográfico, demonstrando presença de consolidação óssea.

O protocolo anestésico utilizado possibilitou o procedimento cirúrgico, sendo necessária apenas uma reaplicação complementar da metade da dose inicial de indução, decorridos trinta minutos da primeira aplicação. A via de aplicação utilizada, para a administração do anestésico, demonstrou ser uma opção viável.

Quanto ao procedimento cirúrgico, a redução da fratura, utilizando o fio intramedular, foi considerada adequada, conferindo satisfatória estabilidade para o processo de formação do calo ósseo. Após o procedimento cirúrgico, decorridos 25 dias, constatou-se, 


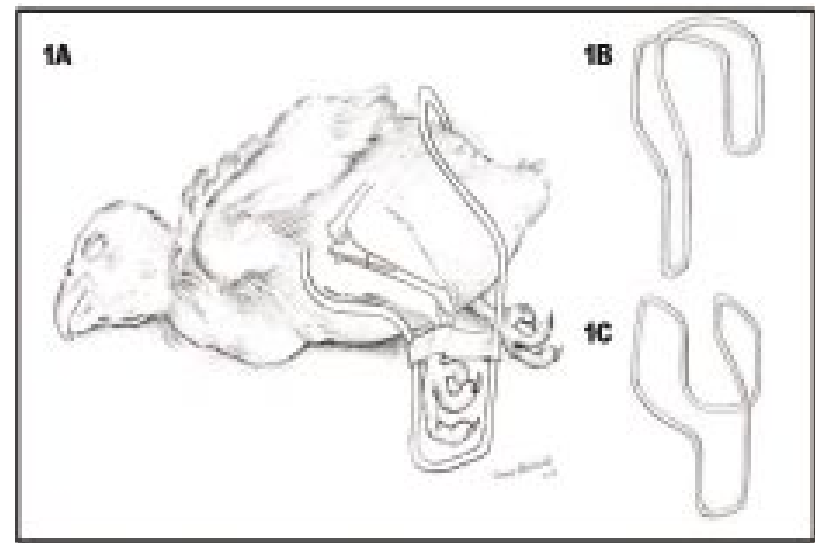

Figura 1. Esquema demonstrando método de redução de fratura em tibiotarso de cacatua. Em A, aparelho de Thomas modificado; em $\mathbf{B}$, aparelho Thomas modificado em formato de sela, vista frontal; em $\mathbf{C}$, aparelho Thomas modificado em formato de sela, vista lateral.

ao exame clínico, ausência de movimentação entre as extremidades ósseas da fratura. Além das informações obtidas no exame clínico, a avaliação radiográfica confirmou a formação e início da consolidação do calo ósseo. A remoção do fio intramedular foi realizada aos 35 dias decorridos da cirurgia, ocasião em que o exame radiográfico demonstrou que a consolidação óssea já era significativa.

O uso do aparelho de Thomas modificado nos primeiros 20 dias, além de proporcionar adequada adaptação ao membro do animal (Figura 2), auxiliou na manutenção da estabilidade conseguida pelo fio intramedular, minimizando a movimentação dos fragmentos ósseos, limitando o afastamento e rotação da fratura ou sobreposição dos fragmentos.

A ausência de sinais clínicos sugestivos de comprometimento circulatório no local da fratura, tais como edema, cianose e necrose, associados à facilidade com que a ave se locomovia, indicaram que a imobilização obtida com a muleta de Thomas foi satisfatória.

\section{DISCUSSÃO}

Não foram observados sinais que inviabilizassem o uso da associação tiletamina-zolazepam em cacatua, apesar de alguns autores [6] não terem recomendado a manutenção anestésica com fármacos dissociativos em aves. Por outro lado, conforme reportado em trabalho anterior, utilizando o mesmo protocolo adotado para o procedimento acima descrito, os autores afirmaram que doses de tiletamina entre 5 e $10 \mathrm{mg} / \mathrm{kg}$ de peso corporal foram efetivas em

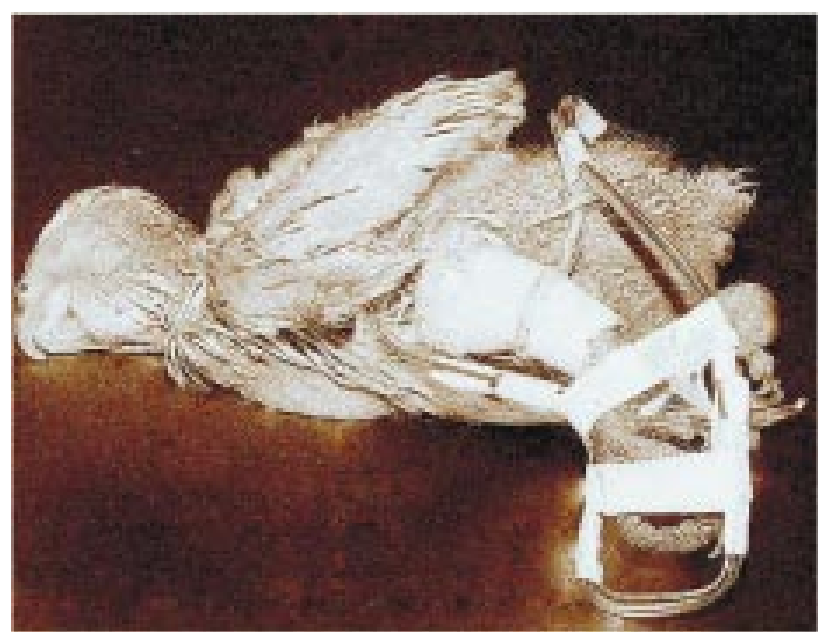

Figura 2. Fotografia da cacatua imediatamente após o procedimento cirúrgico, demonstrando a adequação do aparelho de Thomas modificado ao membro operado.

corujas, e que a associação tiletamina-zolazepam mostrou ser segura para inúmeras espécies de aves [11].

A estabilidade conferida pelo pino intramedular verificada no presente caso, apesar de controversa quando se utiliza a pinagem como método isolado de redução de fraturas, encontrou respaldo em trabalhos anteriormente publicados [3]. Em estudo com psitacídeos portadores de fratura de membro pélvico, observou-se que a utilização do pino intramedular é um método seguro, que proporciona alinhamento anatômico e estabilidade adequada, sem interferir na formação do calo ósseo, não influenciando na funcionabilidade do membro acometido[3]. Acredita-se que os resultados obtidos no presente estudo podem ser, em parte, atribuídos à forma de estabilização e ao pequeno intervalo entre os fragmentos, o que, de acordo com determinados autores, possibilita maiores chances de ocorrer cicatrização óssea por primeira intenção[2,8].

O intervalo entre a implantação e a remoção do pino intramedular, aos 35 dias, foi relativamente menor do que o apresentado por outros autores [1] ao utilizarem pinos intramedulares na osteossíntese de úmero em Arara ararauna (Arara Canindé). Nesses, a presença de calo ósseo, com desaparecimento da linha de fratura, foi observada 60 dias após o procedimento cirúrgico. A redução no tempo de consolidação da fratura, e a presença de calo ósseo no animal do estudo contrariam as afirmações descritas em estudos anteriores, de que a presença do pino metálico pode influenciar negativamente na reparação óssea [9].

Quanto aos resultados observados com a utilização do aparelho de Thomas modificado, os achados 
corroboram com as informações descritas na literatura [5], ao afirmar que tal método, geralmente, permite que a consolidação ocorra em tempo menor se comparado à sua não utilização.

Com relação à cacatua, o aparelho de Thomas apresentou adequada estabilização das extremidades ósseas, possivelmente proporcionado pela adaptação ao corpo da ave e pela rigidez do material utilizado na sua confecção. De acordo com outros trabalhos [12], o uso do aparelho de Thomas como método único de redução de fratura, limita-se, principalmente, ao tamanho do animal, peso, temperamento, tipo de fratura e osso afetado. Acerca da associação da muleta de Thomas com o pino intramedular, os mesmos afirmaram que o método de fixação externa possui grande eficiência, e deve ser considerado como um auxílio quase que indispensável quando se deseja obter melhor estabilização do foco da fratura, principalmente como adjuvante nas imobilizações internas. Apesar de avaliado em espécie diferente à apresentada no presente caso, alguns estudos [10] afirmaram que, a associação do aparelho de Thomas modificado à pinagem intramedular, permite a remoção antecipada do pino, em decorrência do desenvolvimento satisfatório do calo ósseo, fato também evidenciado de forma semelhante com relação à cacatua.

Diante de tais resultados, observou-se que o método de pinagem intramedular, associado ao aparelho de Thomas modificado, permitiu satisfatória estabilidade ao foco da fratura e adequada formação do calo ósseo, sendo considerado eficiente método auxiliar na redução de fratura de tibiotarso em cacatua.

\section{NOTAS INFORMATIVAS}

${ }^{1}$ Zooletil $^{\circledR}$. Virbac do Brasil. São Paulo, SP/Brasil.

2 Tramaliv $^{\circledR}$. Laboratório Teuto Brasileiro S.A. Anápolis, $\mathrm{GO} /$ Brasil.

${ }^{3}$ Terramicina ${ }^{\circledR}$. Laboratório Pfizer Ltda. São Paulo, SP/Brasil.

${ }^{4}$ Banamine $^{\circledR}$. Schering-Plough Saúde Animal Indústria e Comércio Ltda. Cotia, SP/Brasil.

\section{REFERÊNCIAS}

1 Alievi M.M., Schossler J.E. \& Teixeira M. 1998. Osteossíntese de úmero em arara-canindé (Arara ararauna): relato de caso. Clínica Veterinária. 15: 18-20.

2 Bennett R.A. \& Kusma A.B. 1992. Fracture management in birds. Journal of Zoo and Wildife Medicine. 23: 5-38.

3 Castro P.F., Matera J.M., Fantoni D.T. \& Guimarães M.B. 2004. Uso do pino de aço intramedular na reparação de fraturas de ossos longos em psitacídeos: arara-azul (Anodorhynchus hyacinthinus), arara-canindé (Ara ararauna) e papagaio-verdadeiro (Amazona aestiva). Clínica Veterinária. 52: 56-64.

4 Galvão S.R., Carlo R.J., Vargas M., Maia Filho A. \& Gueiros V.A. 1999. Avaliação das alterações ósseas após emprego de placas ortopédicas de aço inoxidável e placas confeccionadas a partir de policloreto de vinila (PVC) na mandíbula de cães. Veterinária Notícias. 1: 25-33

5 Gueiros V.A. \& Borges A.P.B. 1999. Fixação esquelética externa e sua aplicação em pequenos animais - revisão. Clínica Veterinária. 22: 31-36.

6 Guimarães L.D. \& Moraes A.N. 2000. Anestesia em aves: agentes anestésicos. Ciência Rural. 30: 1073-1081.

7 Holz P. 1992. Luxation of the stifle joint in a major mitchell cockatoo. The Veterinary Record. 130: 34.

8 Klein P., Schell H., Streitparth F., Heller M., Kassi J. P., Kandziora F., Bragulla H., Haas N. P. \& Duda G.N. 2003. The initial phase of fracture healing is specifically sensitive to mechanical conditions. Journal of Orthopedic Research. 21:662-669.

9 Larsen I.H. 1952. Bone surgery. Australian Veterinary Journal. 28: 126-138.

10 Miranda A.H., Silva L.A.F., Garcia D.P., Oliveira K.S., Trindade B.R., Menezes L.B., Silva E.B. \& Silva O.C. 2003. Alterações estruturais e no tipo de imobilização dos membros locomotores de cães (Canis familiaris) utilizando o aparelho de Thomas Modificado. Revista Científica de Medicina Veterinária de Pequenos Animais e Animais de Estimação. 1: 185-190.

11 Paul-Murphy J. \& Fialkowski J. 2001. Injectable anesthesia 263 and analgesia of birds. Online. Disponível em: <http:/ /www.ivis.org/authorforms/contributor_info.asp?ID=450>. Acessado em 07/2007.

12 Schossler D.R.C. \& Schossler J.E. 1991. Correção cirúrgica de luxação medial de patela em cão. Revista Cães Gatos. 6: 4-7.

13 Williams R., Holland M. \& Milton J.L. 1987. A comparative study of treatment of methods for long bone fractures. Companion Animal Practice. 1: 48-55. 